Editorial

\title{
Inhaled Corticosteroids: The Endocrine and Metabolic Complications
}

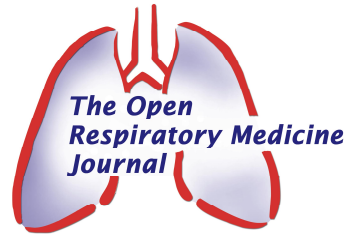

\author{
Joseph M. Pappachan ${ }^{*} \S$
}

\section{Department of Endocrinology, Walsall Manor Hospital, West Midlands, WS2 9PS, UK}

Inhaled corticosteroids (ICS) form a major part of the available therapeutic armamentarium for treatment of crippling chronic respiratory illnesses such as bronchial asthma (BA) and chronic obstructive pulmonary disease (COPD) over the past few decades. The World Health Organization (WHO) estimates that globally 235 million people suffer from BA and 64 million from COPD [1]. These chronic respiratory illnesses force physicians worldwide to prescribe ICS to their patients in their day to day clinical practice. ICS are claimed to predominantly possess local anti-inflammatory effects in the airways without significant systemic adverse effects, compared to oral or parenteral steroids, making them a favourable choice in managing BA and COPD. Intranasal inhalation of steroid aerosols/ powder is also useful in the management of allergic rhinitis. Although the systemic adverse effects of using ICS are claimed to be minimal in managing these chronic respiratory conditions, they do occur in a significant proportion of users, especially at high doses [2].

Suppression of the hypothalamo-pituitary-adrenal axis, adrenal insufficiency, growth retardation in children, Cushing syndrome, cataracts, thinning and bruising of the skin, infections from immune-suppression, and osteoporosis are some of the reported systemic adverse effects from the long-term use of ICS $[2,3]$. The incidence of systemic effects depends on the type and dose of ICS used, the mode of ICS administration and interactions with concurrent use of other medications. The ICS molecules commonly available in the market are beclomethasone dipropionate (BDP), budesonide (BUD), fluticasone propionate (FP), Flunisolide (FLU), mometasone furoate (MF), and ciclesonide (CIC).

Glucocorticoids are powerful steroid hormones secreted by the zona fasciculata of adrenal glands. Soon after the introduction of glucocorticoids for the treatment of systemic diseases in the 1950's, several serious adverse effects were reported $[4,5]$, making them less favoured therapeutic options for the management several chronic illnesses. Many attempts from the scientific fraternity over the past six to seven decades succeeded in developing different steroid

*Address correspondence to this author at the Department of Endocrinology, Walsall Manor Hospital, West Midlands, WS2 9PS, UK; Tel: +44-1922 721172; Fax: +44-1922 721172;

E-mail: drpappachan@yahoo.co.in

${ }^{\S}$ Guest Editor. molecules and administration techniques that minimized the serious systemic adverse effects related to corticosteroids, and the discovery of ICS is a great example of these ventures. The introduction of ICS revolutionised the management of BA since the 1970's, and now there is a global consensus among all professional bodies on regular administration of ICS for treatment of persistent asthma. Although the therapeutic benefits are less convincing, ICS are also used for the management of COPD by many physicians. Corticosteroids have widespread effects in the human body, and this thematic issue focusses on the adverse consequences of ICS on metabolic and endocrine systems of the human body and their management, through a series of review articles from different regions of the world.

In their review "systemic effects of inhaled corticosteroids: an overview" in this issue of the journal, Pandya et al. summarises the overall side effect profile of ICS observed in clinical practice [6]. The authors contradict the popular belief on the safety of ICS in the management of chronic respiratory illnesses such as BA and COPD, with adequate scientific evidence. Although less common when compared to systemic steroids, several systemic adverse effects occur in a few ICS users (especially at high doses) that can involve the hypothalmo-pituitary-adrenal (HPA) axis, bone, skin, eyes, skeletal growth, carbohydrate metabolism and immunity. Animal models showed convincing evidence of an elevated risk for endocrine and metabolic disorders in offspring when ICS was used during pregnancy. With strong evidentiary support from a recent cohort study in pregnant women [7], the authors also bring to attention the potential adverse complications related to ICS use during pregnancy.

The adverse consequence of ICS use on linear growth in children has been an area of hot debate among paediatricians over the past few decades. A follow-up study of the Childhood Asthma Management Program (CAMP) trial participants convincingly proved a detrimental effect of ICS use in pre-pubertal children on their adult height [8]. Severe systemic illnesses including BA can retard growth in children and proper control of BA can positively affect growth velocity. As ICS is the best therapeutic option for control of persistent childhood asthma, a beneficial effect on linear growth is expected in the users. However, the use of steroids during childhood retards linear growth velocity, which results in a reduction of expected height in adulthood. Although the systemic bioavailability of ICS is minimal, at 
high doses, sufficient amount of steroids reaches the systemic circulation and skeletal tissues that suppresses the growth plates of children.

In his article entitled "The effects of inhaled corticosteroids on growth in children" in this issue of the journal, Philip J. debates the different aspects of ICS on growth in children and compiles evidence showing the detrimental effects of ICS on childhood growth [9]. The systemic bioavailability of ICS differs with the type, mode of administration, pharmacokinetic and pharmacodynamic properties of ICS used that determines the risk of adverse consequences on growth velocity in childhood. The United States Food and Drug Administration (FDA) has published clear guidance to avoid bias related to growth monitoring in ICS users. Unfortunately, most studies exploring the effects of ICS on childhood growth to date do not comply with FDA guidance, and therefore, there is still uncertainty on the ideal molecule, optimal dose, type of inhaler device and the method of administration to avoid ICS-related growth retardation in children [10].

Cushing's syndrome (CS) is a state of glucocorticoid excess (hypercortisolism) characterised by truncal obesity, abnormal facial and cervical fat distribution, hypertension, glucose intolerance, myopathy and osteoporosis. Hypercortisolism may be caused by endogenous overproduction or more commonly exogenous administration of glucocorticoids. Although iatrogenic CS is usually a complication of prolonged use of corticosteroids at high doses for systemic diseases, occasional cases of iatrogenic CS can result from ICS treatment. Corticosteroids are metabolised by hepatic cytochrome P450 enzyme system (especially the iso-enzyme CYP3A4). Drugs that interfere with this enzyme system can delay the metabolic clearance of glucocorticoids from the body and can result in iatrogenic $\mathrm{CS}$ even with low doses of exogenous steroids. As the systemic bioavailability of ICS is low, they usually do not cause iatrogenic CS. However, when co-administered with interacting medications such as anti-retroviral agents that interfere with CYP3A4, ICS can result in iatrogenic CS [11].

A detailed account of the pathophysiology, clinical features, diagnostic algorithm and management aspects of different types of CS, especially that complicates ICS use, is discussed by Raveendran AV. in his review "Inhaled corticosteroids and iatrogenic Cushing syndrome" in this issue of the journal [12]. Raveendran also discusses the pharmacokinetics and pharmacodynamics of different ICS molecules and intranasal corticosteroids (INC) commonly used in day to day clinical practice. Many medications can affect the metabolic fate of ICS and INC through the interaction with hepatic cytochrome P450 enzyme system, and may result in iatrogenic $\mathrm{CS}$ in patients on inhalational steroid therapy. The review alerts physicians on the rational use of different medications that can interact with ICS and INC when co-administered with them [12].

Steroid hormones can affect bone metabolism and extrinsic steroid administration is the most common cause of metabolic bone disease and iatrogenic osteoporosis. Metabolic bone disease as a complication of chronic steroid administration was reported in the 1950's within a few years of the introduction of glucocorticoids for management of systemic diseases $[4,5]$. Normal bone homeostasis depends on a balanced function of three types of cells in the skeletal tissues namely, osteoblasts, osteocytes and osteoclasts. Through multiple complex and interlinked mechanisms, chronic administration of glucocorticoids adversely affects the function of these cells that results in metabolic bone disease [13-15]. Osteopenia, osteoporosis and osteonecrosis are the metabolic bone diseases that complicate chronic steroid therapy.

Glucocorticoid-induced osteoporosis (GIO) can occur with a daily steroid dose of more than $5 \mathrm{mg}$ of prednisolone (or equivalent doses of other corticosteroids) over a month, especially in individuals with other risk factors for osteoporosis [14]. The American College of Rheumatology (ACR) published guidelines [16] on the diagnosis and management of GIO in 2010. Even though GIO is uncommon in ICS users because of the low systemic steroid bioavailability, chronic high-dose administration and coexistent risk factors for osteoporosis can make them vulnerable to the disease. Co-administration of drugs that interact with glucocorticoids through hepatic CYP3A4 enzyme system poses a higher risk to ICS users in developing GIO and osteonecrosis [17]. There are no formal recommendations on the diagnostic evaluation and management of steroid-induced metabolic bone disease for ICS users. Through their review article "Inhaled corticosteroids and bone health" in this issue of the journal, Chee et al. [18] elaborate on the mechanisms of steroidinduced metabolic bone disease and put forth an evidencebased diagnostic and therapeutic algorithm for ICS-induced metabolic bone disease with reference to the ACR guidelines. This review is a valuable guide to physicians in the management of patients with chronic respiratory illnesses requiring ICS treatment.

Suppression of the HPA axis induced by chronic extrinsic steroid administration is well-known for many decades. The adrenal steroid response to stressful situations in patients on long-term corticosteroid therapy is subnormal and sometimes may precipitate a potentially lethal medical emergency known as adrenal crisis. Although, HPA axis suppression is less often encountered in patients on ICS therapy, it can occur in few patients especially on high doses of ICS [19]. A review by Sannarangappa et al. [20] in this issue of the journal alerts clinicians about this potential complication of ICS therapy, its clinical presentation, and strategies for evaluation and management.

Last but not the least, is the dysglycemic state as an adverse metabolic complication of steroid therapy. Worsening of pre-existent diabetes, new-onset diabetes or transient hyperglycemia in the immediate treatment period are common and well-known complications of chronic steroid administration, and glucocorticoid therapy is the most common cause of drug-induced diabetes [21]. As chronic lung diseases are common, and with diabetes reaching epidemic proportions, physicians should be vigilant when prescribing steroids to patients with asthma and COPD.

Although steroid-induced dysglycemia is very common, interestingly there are no formal guidelines on the diagnosis and management of the disease (except for the specific management of transplant-related diabetes [22]) from professional bodies. Lansang and Hustak of the Cleveland Clinic have proposed a reasonable algorithm on the 
diagnosis and management of steroid-induced dysglycemia in 2011 with reference to the American Diabetes Association guidelines on diagnosis and management of diabetes in the general population [21]. The algorithm would serve the purpose of assisting clinicians to form a practical approach for diagnosis and management of glucocorticoid-induced diabetes.

Even if the systemic bioavailability is minimal with low to moderate doses of the ICS molecules commonly used for treating respiratory diseases, significant amount of the steroid can reach the circulation to cause adverse effects including a dysglycemic state at high doses administered. An article by Egbuonu et al. [23] in this issue of the journal examines the evidence for this association and proposes a practical approach to managing patients with ICS-related dysglycemic state. Frequent use of rescue steroids for exacerbations of chronic lung diseases further perpetuates the risk of ICS-induced dysglycemia.

In conclusion, the systemic adverse effects related to the endocrine and metabolic systems from ICS use are not uncommon, although the awareness of such effects is inadequate among the scientific fraternity. Physicians should be aware of the emergence of these complications while managing their patients, considering the devastating consequences of a delay in diagnosis and management. A detailed discussion of individual endocrine and metabolic complications related to regular ICS therapy by various experts, published in this thematic issue of the journal, equips readers worldwide with the ability to understand and practice medicine more rationally to manage patients suffering from chronic respiratory illnesses globally.

\section{ACKNOWLEDGEMENTS}

I thank all peer reviewers listed below who helped me by critically reviewing and suggesting modifications of the articles that improved the quality of papers published in this thematic issue.

Dr. Sunil K. Munshi, MD, FRCP, Consultant Physician, Nottingham University Hospitals, Nottingham, United Kingdom.

Dr. Mohamed Musthafa. MD, DTCD, Associate Professor in Chest Diseases, Calicut Medical College, Kerala, India.

Dr. Ambika P Ashraf. MD, Associate Professor in Pediatrics, Division of Pediatric Endocrinology, University of Alabama at Birmingham, USA.

Dr. M.P. Jayakrishnan MD, DCH, Associate Professor in Pediatrics, Calicut Medical College, Kerala, India.

Dr. Mohammed Harriss MD, MRCP, Pulmonologist, Al Zahra Hospital, Dubai and Sharjah, UAE.

Dr. Rajagopalan Sriraman PhD FRCP, Consultant, Department of Endocrinology, Lincoln County Hospital, Lincoln, UK.

Dr. C. Nishal Raveendran MD, MRCP, Hospitalist, Geinsinger Medical Center, Danville, Pennsylvania, USA.
Dr. Ganesan Arunagirinathan, MD, MRCP, Consultant Physician, Department of Endocrinology, Western General Hospital, Edinburgh, UK.

Dr. P.V. Santhosh Kumar MD, DTCD, Associate Professor in Chest Diseases, Kottayam Medical College, Kerala, India.

Prof. Gustavo Duque PhD, FRACP, Professor of Medicine \& Director of Musculoskeletal Ageing Research Program, The University of Sydney, Australia.

Dr. Immo M-A Weichert MRCP (UK) MRCP (Edin), Department of Acute Medicine, The Ipswich Hospital NHS Trust, Ipswich IP4 5PD, UK.

Viera Doničová MD., PhD, Associate Professor, Department of Internal Medicine \& Diabetes, Human Care sro., Rastislavova 45, 04001 Košice, Slovakia.

\section{Cover Design}

Dr. A.V. Raveendran MD, Assistant Professor, Department of Internal Medicine, Kottayam Medical College, Keral, India-686008.

\section{REFERENCES}

[1] World Health Organization. Chronic respiratory diseases 2011. Geneva: World Health Organization. http://www.who.int/ respiratory/about_topic/en/ Accessed on 02 September 2014.

[2] Raissy HH, Kelly HW, Harkins M, Szefler SJ. Inhaled corticosteroids in lung diseases. Am J Respir Crit Care Med 2013; 187: 798-803.

[3] Kelly HW. Potential adverse effects of inhaled corticosteroids. J Allergy Clin Immunol 2003; 112: 469-78.

[4] Bollet AJ, Black R, Bumin JJ. Major undesirable side-effects resulting from prednisolone and prednisone. JAMA 1955; 157: 459-63.

[5] Heiman WG, Freiberger RH. Avascular necrosis of the femoral and humeral heads after high-dosage corticosteroid therapy. N Engl J Med 1960; 263: 672-75.

[6] Pandya D, Puttanna A, Balagopal V. Systemic effects of inhaled corticosteroids: an overview. Open Respir Med J 2014; 8: 59-65.

[7] Tegethoff M, Greene N, Olsen J, Schaffner E, Meinlschmidt G. Inhaled glucocorticoids during pregnancy and offspring pediatric diseases: a national cohort study. Am J Respir Crit Care Med 2012; 185: 557-63.

[8] Kelly HW, Sternberg AL, Lescher R, et al. Effect of inhaled glucocorticoids in childhood on adult height. N Engl J Med 2012; 367: 904-12.

[9] Philip J. Effect of inhaled corticosteroids on growth in children. Open Respir Med J 2014; 8: 66-73.

[10] Bartholow AK, Deshaies DM, Skoner JM, Skoner DP. A critical review of the effects of inhaled corticosteroids on growth. Allergy Asthma Proc 2013; 34: 391-407.

[11] Foisy MM, Yakiwchuk EM, Chiu I, Singh AE. Adrenal suppression and Cushing's syndrome secondary to an interaction between ritonavir and fluticasone: a review of the literature. HIV Med 2008; 9: 389-96.

[12] Raveendran AV. Inhaled corticosteroids and iatrogenic Cushing syndrome. Open Respir Med J 2014; 8: 74-84.

[13] Weinstein RS. Glucocorticoid-induced bone disease. N Engl J Med 2011; 365: 62-70.

[14] Buehring B, Viswanathan R, Binkley N, Busse W. Glucocorticoidinduced osteoporosis: an update on effects and management. J Allergy Clin Immunol 2013; 132: 1019-30.

[15] Weinstein RS. Glucocorticoid-induced osteoporosis and osteonecrosis. Endocrinol Metab Clin North Am 2012; 41: 595611. 
[16] Grossman JM, Gordon R, Ranganath VK, et al. American College of Rheumatology 2010 recommendations for the prevention and treatment of glucocorticoid-induced osteoporosis. Arthritis Care Res (Hoboken) 2010; 62: 1515-26.

[17] Kaviani N, Bukberg P, Manessis A, Yen V, Young I. Iatrogenic osteoporosis, bilateral HIP osteonecrosis, and secondary adrenal suppression in an HIV-infected man receiving inhaled corticosteroids and ritonavir-boosted highly active antiretroviral therapy. Endocr Pract 2011; 17: 74-78.

[18] Chee C, Sellahewa L, Pappachan JM. Inhaled corticosteroids and bone health. Open Respir Med J 2014; 8: 85-92.

[19] Todd GR, Acerini CL, Ross-Russell R, Zahra S, Warner JT, McCance D. Survey of adrenal crisis associated with inhaled corticosteroids in the United Kingdom. Arch Dis Child 2002; 87: 457-61.

[20] Sannarangappa V, Jalleh R. Inhaled corticosteroids and secondary adrenal insufficiency. Open Respir Med J 2014; 8: 93-100.

[21] Lansang MC, Hustak LK. Glucocorticoid-induced diabetes and adrenal suppression: how to detect and manage them. Cleve Clin J Med 2011; 78: 748-56.

[22] Davidson J, Wilkinson A, Dantal J, et al. International Expert Panel. New-onset diabetes after transplantation: 2003 international consensus guidelines. Proceedings of an international expert panel meeting. Barcelona, Spain, 19 February 2003. Transplantation 2003; 75(suppl 10): SS3-24.

[23] Egbuonu F, Antonio FA, Edavalath M. Effect of Inhaled corticosteroids glycemic status. Open Respir Med J 2014; 8: 101-5.

(C) Joseph M. Pappachan; Licensee Bentham Open.

This is an open access article licensed under the terms of the Creative Commons Attribution Non-Commercial License (http://creativecommons.org/licenses/by-nc/3.0/) which permits unrestricted, non-commercial use, distribution and reproduction in any medium, provided the work is properly cited. 